\title{
Increased Amplitude of Thalamocortical Low-Frequency Oscillations in Patients with Migraine
}

\author{
Duncan J. Hodkinson, ${ }^{1}$ Sophie L. Wilcox, ${ }^{1}$ Rosanna Veggeberg, ${ }^{1}{ }^{\circledR}$ Rodrigo Noseda, ${ }^{2}$ - Rami Burstein, ${ }^{2}$ David Borsook, \\ and Lino Becerra ${ }^{1}$ \\ ${ }^{1}$ Department of Anesthesiology, Perioperative and Pain Medicine, Boston Children's Hospital, Harvard Medical School, Boston, Massachusetts 02115, and \\ 2Department of Anesthesia, Critical Care and Pain Medicine, Beth Israel Deaconess Medical Center, Harvard Medical School, Boston, Massachusetts 02215
}

For many years, neurobiological theories have emphasized the importance of neuronal oscillations in the emergence of brain function. At the same time, clinical studies have shown that disturbances or irregularities in brain rhythms may relate to various common neurological conditions, including migraine. Increasing evidence suggests that the CNS plays a fundamental role in the predisposition to develop different forms of headache. Here, we present human imaging data that strongly support the presence of abnormal low-frequency oscillations (LFOs) in thalamocortical networks of patients in the interictal phase of migraine. Our results show that the main source of arrhythmic activity was localized to the higher-order thalamic relays of the medial dorsal nucleus. In addition, spontaneous LFOs in the thalamus were selectively associated with the headache attack frequency, meaning that the varying amplitude of dysrhythmia could predispose patients to recurrent attacks. Rhythmic cortical feedback to the thalamus is a major factor in the amplification of thalamocortical oscillations, making it a strong candidate for influencing neuronal excitability. We further speculate that the intrinsic dynamics of thalamocortical network oscillations are crucial for early sensory processing and therefore could underlie important pathophysiological processes involved in multisensory integration.

Key words: frequency; headache; migraine; oscillations; pain; thalamocortical

Significance Statement

In many cases, migraine attacks are thought to begin centrally. A major obstacle to studying intrinsic brain activity has been the identification of the precise anatomical structures and functional networks that are involved in migraine. Here, we present imaging data that strongly support the presence of abnormal low-frequency oscillations in thalamocortical networks of patients in the interictal phase of migraine. This arrhythmic activity was localized to the higher-order thalamic relays of the medial dorsal nucleus and was selectively associated with headache attack frequency. Rhythmic cortical feedback to the thalamus is a major factor in the amplification of thalamocortical oscillations, making it a strong candidate for influencing neuronal excitability and higher-level processes involved in multisensory integration.

\section{Introduction}

Migraine is one of the most prevalent disorders throughout the world (Vos et al., 2012). Attacks are usually characterized by unilateral, pulsating head pain that is associated with nausea and can include sensitivity to light, sound, and touch (Headache Classification Subcommittee of the International Headache Society,

Received March 29, 2016; revised June 13, 2016; accepted June 16, 2016.

Author contributions:D.J.H., D.B., and L.B. designed research;D.J.H., R.V., R.B., D.B., and L.B. performed research; D.J.H., S.L.W., R.V., R.N., R.B., and L.B. contributed unpublished reagents/analytic tools; D.J.H. analyzed data; D.J.H. wrote the paper.

This work was supported by the National Institutes of Health (Grants R01 NS073977 and K24 NS064050).

The authors declare no competing financial interests.

Correspondence should be addressed to Dr. Duncan J. Hodkinson, Department of Anesthesiology, Perioperative and Pain Medicine, Boston Children's Hospital, Harvard Medical School, 1 Autumn Street, Boston, MA 02115. E-mail: duncan.hodkinson@childrens.harvard.edu.

DOI:10.1523/JNEUROSCI.1038-16.2016

Copyright $\odot 2016$ the authors $\quad 0270-6474 / 16 / 368026-11 \$ 15.00 / 0$
2004). Not all of these features are present in every attack or in every patient (Hansen et al., 2016; Viana et al., 2015), but increasing evidence suggests that the mechanisms responsible for the clinical symptomatology may in part involve dysfunction of the CNS (Goadsby et al., 2009; Burstein et al., 2015; Ferrari et al., 2015).

Human electrophysiology studies have revealed consistent abnormalities in cortical responsivity to external stimuli during the different phases of the migraine cycle (de Tommaso et al., 2014). This is usually characterized by habituation deficits in stimulus repetition and reflex responses (Coppola et al., 2013), which appear to have a strong familial pattern of inheritance (Sándor et al., 1999; Siniatchkin et al., 2000; Siniatchkin et al., 2001; Di Clemente et al., 2007). These cortical habituation deficits have been observed across several sensory modalities, leading to the hypothesis that migraine patients may have a reduced preactivation 
status in sensory cortices between attacks (Schoenen, 1996). Efforts to modulate cortical excitability using noninvasive neurostimulation techniques has revealed selective efficacy for reducing attack frequency and intensity in patients (Teepker et al., 2010; Antal et al., 2011; Viganò et al., 2013; Diener et al., 2015). These findings have led to the proposal that alterations in the trigeminovascular system may cause neuronal dysexcitability in genetically susceptible individuals (Coppola et al., 2007a; Pietrobon and Moskowitz, 2013; Ferrari et al., 2015) through a direct relationship with thalamocortical rhythmicity (Coppola et al., 2007a). Alternatively or cocomitantly, the migraine attack may arise from defective brainstem and diencephalon circuits that fail to regulate neuronal excitability at multiple levels of the trigemino-cortical pathway (Bahra et al., 2001; Akerman et al., 2011; Boyer et al., 2014).

A major obstacle to studying intrinsic oscillatory activity lies in identification of the precise anatomical structures and functional networks that are involved in migraine. Although the high temporal resolution of electrophysiological methods makes them particularly well suited for studying rapidly evoked changes in brain function, EEG/event-related potential methods lack strong spatial resolution capabilities. Recently, low-frequency oscillations (LFOs) have gained increased attention based on observations using functional magnetic resonance imaging (fMRI) (Biswal et al., 1995; Fox et al., 2005; Fox and Raichle, 2007). Using these modalities, researchers have consistently identified coherent spontaneous low-frequency fluctuations (typically at frequencies $<0.1 \mathrm{~Hz}$ ) during both resting-state and active-task conditions that are thought to reflect cyclic modulation of cortical excitability and long distance neuronal synchronization (Deco et al., 2011; Power et al., 2014). Despite the increased awareness of LFOs in resting-state fMRI data, the amplitude and regional characteristics of spontaneous LFOs have not been examined in patients with migraine.

In the present study, we compared the spatial distribution of the fractional amplitude of low-frequency fluctuations (f/ALFF) (Zang et al., 2007; Zou et al., 2008; Zuo et al., 2010) systematically in a large cohort of migraine patients $(n=40)$ and matched healthy controls $(n=40)$. Resting-state fMRI measurements based on the blood-oxygen-level-dependent (BOLD) signal are believed to reflect the intensity of the input and intracortical processing of a given area rather than its spiking output (Logothetis, 2008), providing a basis for a more localized measure of the LFO phenomena (Zuo et al., 2010). We hypothesized that internally generated LFO activity would be disrupted in patients with migraine, leading to an abnormal interictal state-dependent flow of information between the thalamus and cortex. This in turn should be reflected in the symptomatology of the migraine patients, as predicted by their clinical status (i.e., headache frequency and/or disease duration) at the time of the scan.

\section{Materials and Methods}

Participants. A total of 80 adult volunteers ( 40 episodic migraine patients and 40 healthy controls) were selected for this study (mean age \pm SD: $32.7 \pm 9$ years, range $18-50$, right-handed). The participants were individually age and sex matched (age \pm 1 year, 10 males/30 females). Migraine patients reported a mean migraine (disease) duration of $15 \pm 9$ years, range 3-39 years). The attack frequency was recorded as episodes per month $(6.9 \pm 5)$. Most patients reported migraine without aura $(n=$ $24)$, but some reported migraine with aura $(n=16)$. Laterality of headache pain was reported as either unilateral ( $n=10$ right-sided, $n=10$ left-sided) or bilateral $(n=20)$. Informed written consent was obtained from all participants. The Institutional Review Board at McLean Hospital, Harvard Medical School approved the study. All experiments fulfilled the criteria of the Helsinki accord for human research (http://www.wma.net/en/30publications/10policies/b3/).

Inclusion/exclusion criteria. Before enrollment, participants underwent physical and neurological examinations. Migraine patients had to meet the following criteria to be enrolled into the study: (1) episodic migraine as classified in the International Classification for Headache Disorders (ICHD) Second Edition (II) (Headache Classification Subcommittee of the International Headache Society, 2004); (2) episodic migraine for $\geq 3$ years; and (3) no migraine $72 \mathrm{~h}$ before the study session and no symptoms of developing a migraine $24 \mathrm{~h}$ after the scans.

In addition, a detailed medical history was taken from both patients and controls. Patients were excluded if they had continuous background headache or pain, chronic migraine, or were taking daily medication including prophylactic migraine treatment. Healthy controls were excluded if they had any type of migraine or first-degree relatives with a history of any type of migraine. Females were excluded if they were pregnant.

MRI data acquisition. Participants were scanned in a $3 \mathrm{~T}$ whole-body MRI scanner with a standard 12-channel receive-only head coil (Siemens Healthcare). For reference purposes, a high-resolution T1-weighted anatomical scan was acquired using a $3 \mathrm{D}$ magnetization-prepared rapid gradient echo sequence $($ MPRAGE, TI $=1100 \mathrm{~ms}$, TR/TE $=2000 / 3.5$ ms, flip angle $=8^{\circ} \mathrm{FOV}=256 \mathrm{~mm}^{2}$, matrix $=256 \times 256,224$ slices, voxel size $1 \times 1 \times 1 \mathrm{~mm})$. Resting-state $\mathrm{fMRI}$ data were acquired using a $2 \mathrm{D}$ gradient-echo echoplanar imaging sequence (GE-EPI, TE/TR $=30 /$ $2010 \mathrm{~ms}$, flip angle $=90^{\circ} \mathrm{FOV}=224 \mathrm{~mm}^{2}$, matrix $=64 \times 64$, number slices $=34$, slice thickness $=4 \mathrm{~mm}$, no gap, voxel size $=3.5 \times 3.5 \mathrm{~mm}^{2}$, number of volumes $=300$, total scan time $=10 \mathrm{~min}, 5 \mathrm{~s}$ ). Slices were acquired in interleaved-ascending order, parallel to the anterior commissure-posterior commissure line. All participants were instructed to keep their eyes open.

Image preprocessing. All imaging data were preprocessed using SPM12 (http://www.fil.ion.ucl.ac.uk/spm) and customized scripts written in MATLAB Version R2015a (The MathWorks ). In accordance with previously described ALFF (Zang et al., 2007) and f/ALFF (Zou et al., 2008) studies, the steps involved in the pipeline included: (1) dropping volumes: the first four volumes of each run were discarded to allow for T1-equilibration effects; (2) slice timing correction: compensation for slice-dependent time shifts were corrected per volume; (3) motion correction: rigid body translation and rotation from each volume to the first volume were used to correct for head motion; (4) spatial normalization: normalization was achieved by computing affine and nonlinear transforms of the mean motion-corrected image to the Montreal Neurological Institute (MNI) BOLD EPI template; (5) spatial smoothing: data were resampled to $2 \mathrm{~mm}$ isotropic voxels and spatially smoothed using a $6 \mathrm{~mm}$ full-width half- maximum Gaussian kernel; and (6) motion regression: spurious nonspecific variance were removed through the use of the six parameters obtained by rigid body head motion correction and their first derivatives.

No temporal filtering or tissue-based signal regression was implemented during the preprocessing. Motion scrubbing was also excluded because the removal of noncontiguous time points alters the underlying temporal structure of the data and thus should not be implemented before fast-Fourier transformation.

Computing f/ALFF. ALFF (Zang et al., 2007) and f/ALFF (Zou et al., 2008) are related measures that quantify the amplitude of LFOs. Here, we used the f/ALFF measure because it has been shown to suppress nonspecific signal components in resting-state fMRI data, providing improved sensitivity and specificity to detect regional spontaneous brain activity (Zuo et al., 2010). In addition, it has been shown that gross pulsatile effects can be attenuated using f/ALFF (Zuo et al., 2010), which should help to exclude artifacts that disproportionately affect subcortical and periventricular regions. Before the statistical analyses, each individual f/ALFF map was $Z$-transformed (i.e., by subtracting the mean voxelwise f/ALFF obtained from the individual's entire brain and then dividing by the corresponding SD). Assessments of the temporal stability of f/ALFF values have shown that there is no significant difference between either raw or standardized f/ALFF maps (Küblböck et al., 2014). However, standardized $Z$-score distributions are more likely to be normal than the 

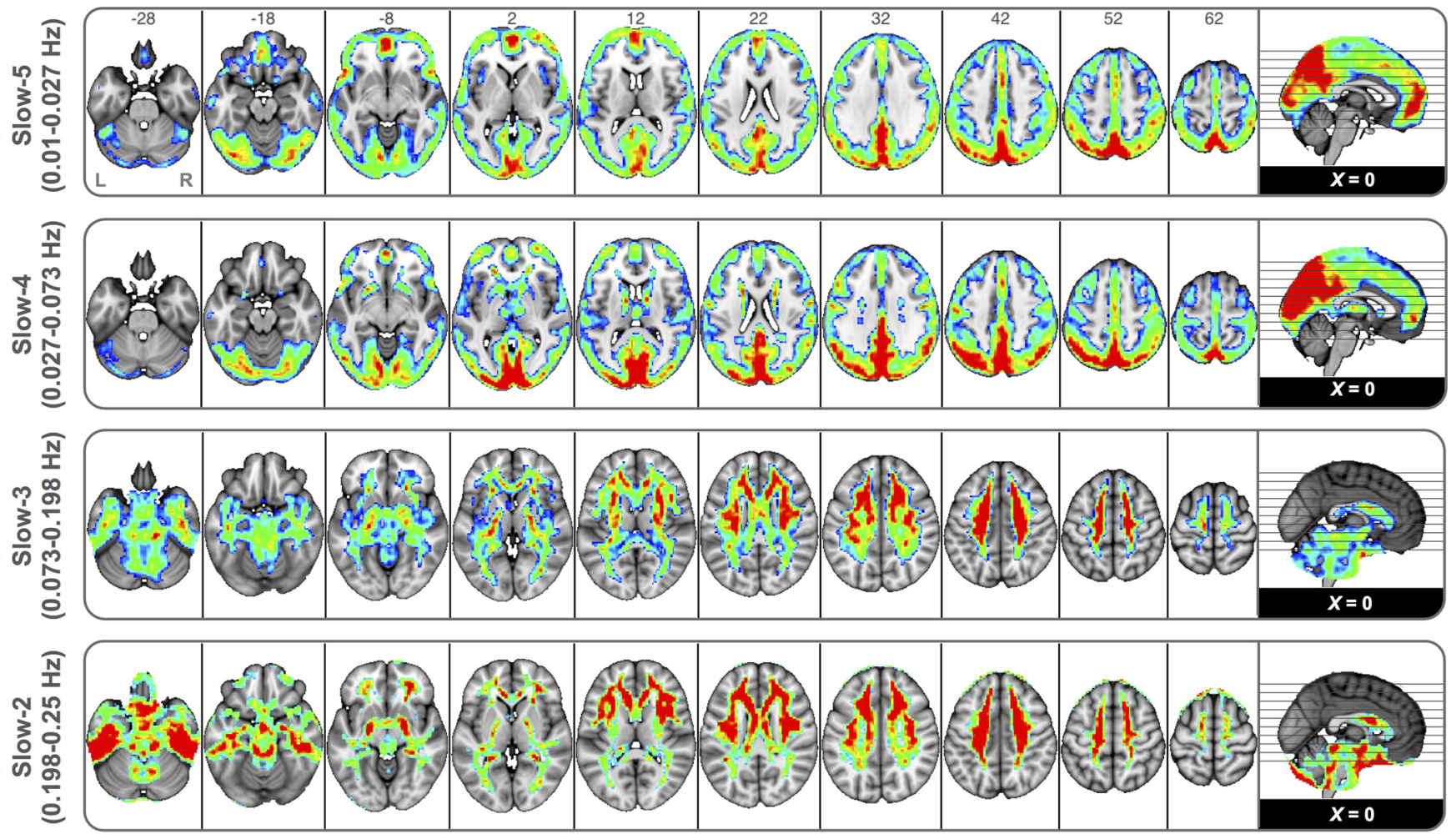

T-score (FWE-corrected)

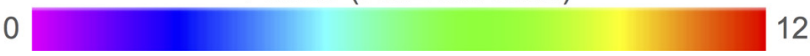

Figure 1. Amplitude of spontaneous LFOs in the resting brain. The statistical maps illustrate the detectable fractional amplitude of $f / A L F F s$ across all subjects in the sample $(n=80)$. Data are separated into 4 frequency bands: slow- $5(0.01-0.027 \mathrm{~Hz})$, slow- $4(0.027-0.073 \mathrm{~Hz})$, slow-3 $(0.073-0.198 \mathrm{~Hz})$, and slow- $2(0.198-0.250 \mathrm{~Hz})$. All statistical images are displayed with a cluster probability threshold of $p<0.05$, corrected for multiple comparisons (familywise error, FWE). The sagittal image on the right displays the position of slices in standard MNI space (gray lines). R (right) and L (left) indicate image orientations for slices in the $Z$ plane.

distributions of the raw measures and therefore will be more suitable for examination using parametric statistics.

We would like to emphasize that the f/ALFF approach is different from most resting-state functional connectivity studies, which focus on mapping the spatial distribution of temporal correlations in the resting-state fMRI signal. Further details of the retest reliability of the f/ALFF technique have been described previously (Zuo et al., 2010; Küblböck et al., 2014).

Isolated frequency bands. Distinct oscillators generate the different frequency bands, each with specific properties and physiological functions. Penttonen and Buzsáki observed that the neuronal oscillation classes are arrayed linearly when plotted on the natural logarithmic scale (Penttonen and Buzsáki, 2003; Buzsáki and Draguhn, 2004). We applied Buzsáki's nomenclature to subdivide the low-frequency range into four discrete bands: slow-5 $=0.010-0.027 \mathrm{~Hz}$; slow- $4=0.027-0.073 \mathrm{~Hz}$; slow-3 $=0.073-0.198 \mathrm{~Hz}$; and slow- $=0.198-0.250 \mathrm{~Hz}$. For each of these subdivisions, we repeated our primary f/ALFF analysis and compared the spatial distribution of the signals between the migraine and control groups.

Group voxelwise analysis. Each of the amplitude images was combined across subjects for display purposes. Group-level statistical comparisons were performed under the framework of the general linear model using a random-effects two-tailed $t$ test (as implemented in the SPM software package). The presented maps are thresholded at $p<0.05$, familywise error rate corrected with a cluster-defining primary threshold of $p<0.01$ $(T=2.43)$.

Region of interest (ROI) analysis. We hypothesized a priori that projections from the thalamus would entrain a core of low-frequency cortical activity. To define an unbiased thalamic mask, we selected the left and right thamalus from the Harvard-Oxford subcortical probabilistic $2 \mathrm{~mm}$ structural atlas. The prior probability images were thresholded at $20 \%$ and binarized to create a single bilateral ROI mask of the thalamus. For each participant, this anatomically defined ROI was used to calculate power spectra density (PSD) of the LFO in the thalamus. In addition, the linear dependence between the amplitude of the LFO and the patient's clinical characteristics (i.e., age, headache frequency, and disease duration) was examined using Pearson's correlation coefficients (significance level $\alpha=0.05$ ).

\section{Results}

\section{Spatial distribution of LFO}

The oscillatory fMRI waves showed a distinct pattern of activity across the four low-frequency bands (Fig. 1). Most notably, slow-5 and slow-4 oscillations occurred predominantly in the gray matter, whereas slow- 3 and slow- 2 oscillations were localized to the white matter. This anatomical segregation of the frequency bands (i.e., slow-5/4 vs slow-3/2) is highly consistent with prior evidence that physiological processes (e.g., respiratory and aliased cardiac signals) fall within the ranges of slow-2/3 (Cordes et al., 2001), whereas the oscillatory signals upon which restingstate functional connectivity is based are primarily located in slow-5/4 (De Luca et al., 2006; Salvador et al., 2008). Accordingly, we found that the areas exhibiting the largest LFO amplitudes in the gray matter (slow-5 and slow-4) were localized to midline structures on the medial wall, which is consistent with prior demonstrations of higher metabolic and neuronal activity during rest (Raichle et al., 2001; Raichle and Mintun, 2006; Vaishnavi et al., 2010) and approximate brain regions that comprise the most prominent intrinsically connected network known as the "default mode" network (Buckner et al., 2008). In contrast, the cer- 

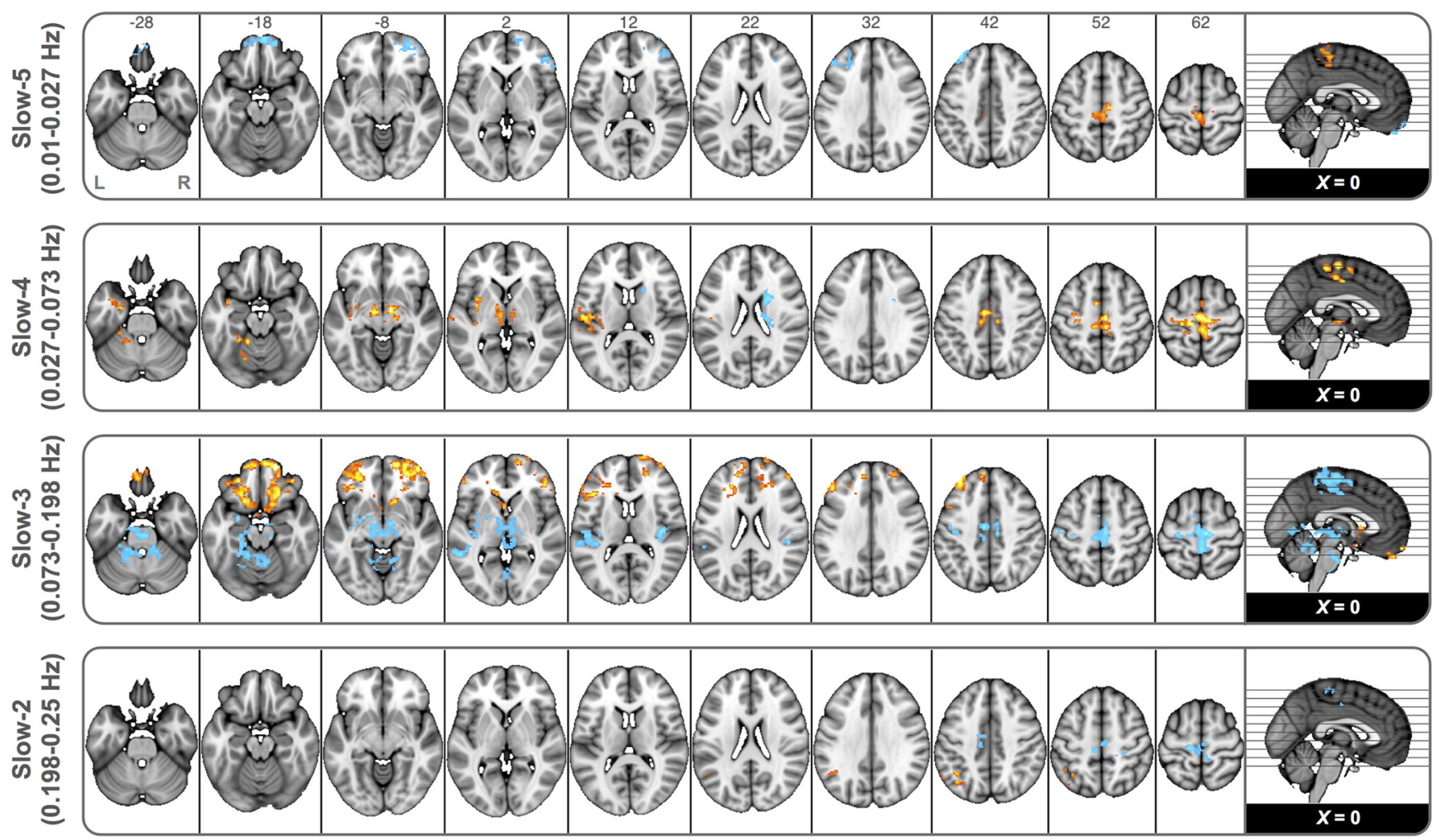

T-score (FWE-corrected)

$-5$ $+5$

Migraine $<$ Controls $<$ Migraine

Figure 2. Frequency-dependent changes in the amplitude of LFOs in migraine. The statistical maps illustrate the differences in fALFF between migraine patients and healthy controls. Data are separated into 4 frequency bands: slow-5 $(0.01-0.027 \mathrm{~Hz})$, slow- $4(0.027-0.073 \mathrm{~Hz})$, slow-3 $(0.073-0.198 \mathrm{~Hz})$, and slow- $2(0.198-0.250 \mathrm{~Hz})$. All statistical images are displayed with a cluster probability threshold of $p<0.05$, corrected for multiple comparisons (familywise error, FWE). The sagittal image on the right displays the position of slices in standard MNI space (gray lines). R (right) and L (left) indicate image orientations for slices in the $Z$ plane.

ebellum and medial temporal lobes had LFO amplitudes significantly below the brain mean, which might reflect a change in the ratio of neurons to non-neuronal cells (Azevedo et al., 2009; Vaishnavi et al., 2010).

\section{Frequency-dependent changes of LFO in migraine}

Group-level statistical comparisons of the LFO amplitudes across the four frequency bands are shown in Figure 2. The results were as follows: slow-5 (0.01-0.027 Hz): higher amplitude in the sensorimotor area (SMA) (medial precentral gyrus) and lower amplitude in prefrontal cortex (including middle frontal gyrus, straight gyrus); slow-4 (0.027-0.073 Hz): higher amplitude in medial temporal lobe (entorhinal area), operculum, thalamus, ventral diencephalon/hypothalamus, and SMA (medial postcentral gyrus) and lower amplitude in right area of the cerebral white matter; slow-3 (0.073-0.198 Hz): higher amplitude in prefrontal cortex (including superior frontal gyrus, middle frontal gyrus, medial orbital gyrus, frontal pole) and lower amplitude in SMA (precentral and postcentral gyrus), operculum, middle temporal gyrus, and brainstem; and slow-2 (0.198-0.25 Hz): higher amplitude in angular gyrus and lower amplitude in the SMA. A full list of local clusters and their respective coordinates are provided in Table 1.

\section{Identification of LFOs in the thalamus}

Figure $3 A$ shows the whole-brain statistical map of the frequencydependent changes in band slow-4. The cortical regions showing disruptions in LFO activity included the insula, operculum, dorsal anterior cingulate cortex, and SMA. The only two subcortical regions that showed altered LFO activity were the ventral diencepahalon (hypothalamus) and thalamus. To characterize the spatial patterns underlying the thalamic oscillatory activity, the atlas by Morel and Krauth (Morel et al., 1997) was used to identify the thalamic nuclei involved (Fig. $3 B)$. The thalamic subdivisions were consistent with the medial dorsal nucleus and small portions of anterior nucleus. We acknowledge that Figure $3 B$ cannot be expected to match the precision of previous histology studies. Based on the imaging protocols, we can only approximately locate the major thalamic nuclei within the MNI template.

\section{Power spectra analysis of thalamic LFO in migraine}

Using the a priori defined ROI of the thalamus, we calculated the PSD of the oscillatory fMRI waves for all of the migraine patients and healthy controls (Fig. $4 A, B$ ). For illustration purposes, the power spectra were averaged across the participants in each group (Fig. $4 C, D$ ). Comparing across the groups, there was a significant increase in the low-frequency bands slow-5 and slow-4, as well as a significant increase in slow-2 (Fig. 4E). These findings were confirmed by plotting a natural logarithmic scale of power against the log of the entire frequency range (Fig. 4F) (Penttonen and Buzsáki, 2003). 
Table 1. Peak MNI coordinates for anatomical regions that had significantly higher and lower f/ALFF amplitude in migraine patients $(n=40)$ compared with controls $(n=40)$

\begin{tabular}{|c|c|c|c|c|c|c|c|c|}
\hline \multirow[b]{2}{*}{ Frequency band } & \multirow[b]{2}{*}{ Contrasts } & \multirow[b]{2}{*}{ Tscore } & \multirow[b]{2}{*}{ Zscore } & \multirow[b]{2}{*}{ Cluster extent } & \multicolumn{3}{|c|}{ MNI coordinates (mm) } & \multirow[b]{2}{*}{ Anatomical region } \\
\hline & & & & & $x$ & $y$ & $Z$ & \\
\hline \multirow[t]{4}{*}{ Slow-5 (0.01-0.027 Hz) } & Migraine $>$ controls & 3.97 & 3.61 & 599 & 4 & -24 & 56 & Right precentral gyrus medial segment \\
\hline & Migraine $<$ controls & 4.81 & 4.24 & 1038 & 6 & 62 & -20 & Right gyrus rectus \\
\hline & & 4.3 & 3.87 & & 48 & 44 & 10 & Right middle frontal gyrus \\
\hline & & 3.99 & 3.63 & 259 & -28 & 28 & 34 & Left middle frontal gyrus \\
\hline \multirow[t]{8}{*}{ Slow-4 (0.027-0.073 Hz) } & Migraine $>$ controls & 4.89 & 4.29 & 1948 & 10 & -38 & 58 & Right postcentral gyrus medial segment \\
\hline & & 4.72 & 4.17 & 534 & 10 & -8 & -8 & Right ventral diencephalon + thalamus* \\
\hline & & 4.06 & 3.68 & & -8 & -10 & -8 & Left ventral diencephalon + thalamus* \\
\hline & & 4.42 & 3.95 & 1078 & -30 & 0 & -24 & Left entorhinal area \\
\hline & & 4.29 & 3.86 & & -46 & -22 & 16 & Left central operculum \\
\hline & Migraine $<$ controls & 4.32 & 3.88 & 361 & 20 & 6 & 22 & Right cerebral white matter \\
\hline & & 4.15 & 3.76 & & 16 & -14 & 18 & Right cerebral white matter \\
\hline & & 3.77 & 3.46 & & 22 & -20 & 22 & Right cerebral white matter \\
\hline \multirow[t]{16}{*}{ Slow-3 $(0.073-0.198 \mathrm{~Hz})$} & Migraine $>$ controls & 5.65 & 4.8 & 4888 & 26 & 56 & -4 & Right middle frontal gyrus \\
\hline & & 5.6 & 4.77 & & 20 & 58 & -18 & Right medial orbital gyrus \\
\hline & & 5.44 & 4.66 & & 18 & 70 & 6 & Right frontal pole \\
\hline & & 4.4 & 3.94 & 354 & -14 & 48 & 24 & Left cerebral white matter \\
\hline & & 4.34 & 3.89 & & -6 & 46 & 46 & Left superior frontal gyrus \\
\hline & & 3.98 & 3.62 & & -24 & 60 & 26 & Left superior frontal gyrus \\
\hline & & 3.96 & 3.61 & 293 & -44 & 34 & 32 & Left middle frontal gyrus \\
\hline & Migraine $<$ controls & 5.2 & 4.51 & 1991 & 6 & -20 & 62 & Right precentral gyrus medial segment \\
\hline & & 5.1 & 4.43 & & 10 & -38 & 56 & Right postcentral gyrus medial segment \\
\hline & & 5.12 & 4.45 & 3137 & 2 & -22 & -30 & Brainstem \\
\hline & & 4.83 & 4.25 & & -18 & -36 & -32 & Left cerebellum white matter \\
\hline & & 4.93 & 4.32 & 281 & 40 & -18 & 12 & Right transverse temporal gyrus \\
\hline & & 4.18 & 3.78 & & 34 & -22 & 16 & Right parietal operculum \\
\hline & & 3.93 & 3.58 & & 50 & -22 & 20 & Right parietal operculum \\
\hline & & 4.42 & 3.96 & 758 & -54 & -46 & 2 & Left middle temporal gyrus \\
\hline & & 4.31 & 3.87 & & -58 & -32 & 14 & Left planum temporale \\
\hline \multirow[t]{3}{*}{ Slow-2 (0.198-0.25 Hz) } & Migraine $>$ controls & 5.72 & 4.85 & 375 & -50 & -56 & 26 & Left angular gyrus \\
\hline & & 5.58 & 4.76 & & -38 & -64 & 46 & Left angular gyrus \\
\hline & Migraine $<$ controls & 4.25 & 3.83 & 537 & 4 & -20 & 58 & Right precentral gyrus medial segment \\
\hline
\end{tabular}

All statistical images were thresholded at $T>2.4$, with a cluster probability threshold of $p<0.05$ corrected for multiple comparisons (FWE).

*Contiguous cluster of voxels extending across two subcortical regions.

\section{Correlations between thalamic LFOs and clinical variables}

Finally, we investigated the relationship between the LFOs in the thalamus and the patients' self-reported (retrospective) symptoms. Associations between PSD and clinical variables (i.e., age, headache frequency, and disease duration) were computed for each of the frequency bands separately using a Pearson correlation (Fig. 5). We found that the amplitude of the PSD in slow-4 was significantly correlated with the patients' self-reported headache attack frequency (per month) at the time of the scan. There was no relationship between the thalamic PSD and the age of the patients or their disease duration. Testing confirms that the data follow a normal distribution and are free from outlier effects (Jarque-Bera test: age, $p=0.186$; frequency, $p=0.081$; duration, $p=0.087)$.

\section{Discussion}

Previous studies using electrophysiological techniques have demonstrated that brain function of migrainie patients is altered across all phases of the migraine cycle (for review, see de Tommaso et al., 2014). These findings have led to the proposal that the symptomatology may in part involve dysfunction of the CNS. Here, we present the first imaging data that strongly support the presence of abnormal LFOs in thalamocortical networks of patients in the interictal phase of migraine. We discuss the possible mechanisms by which aberrant LFO activity may contribute to the dysfunctions and symptoms ascribed to the migraine condition.

\section{Thalamocortical dysrhythmia in migraine}

Beyond confirming prior demonstrations of higher LFO amplitudes within cortical gray matter (Biswal et al., 1995; Cordes et al., 2001), our results provide compelling evidence that intrinsic LFO activity is abnormal in patients with migraine between attacks. Across the frequency range, there was a characteristic shift in synchronized oscillations between slow-3 $(0.073-0.198 \mathrm{~Hz})$ and slow-4 $(0.027-0.073 \mathrm{~Hz})$, favoring the lower-frequency state (Fig. 2). It is well established that power density is inversely proportional to frequency $(f)$ in the mammalian cortex. This $1 / f$ power relationship implies that perturbations occurring at slow frequencies can cause a cascade of energy dissipation at higher frequencies, so widespread slow oscillations can modulate faster local systems. While the exact biological mechanisms of these infra-slow brain oscillations remain unknown (Hughes et al., 2011), it has been suggested that slow waves may be dependent on the time course of $\mathrm{Ca}^{2+}$-mediated $\mathrm{K}^{+}$conductance of cortical neurons (Buzsáki et al., 1988) and hyperpolarizing potentials of thalamocortical cells (Lüthi and McCormick, 1998; Steriade, 2001; McCormick, 2002). Thalamic astrocytes also exhibit spontaneous intracellular $\mathrm{Ca}^{2+}$ oscillations, which occur in a similar frequency range to the LFOs of thalamocortical neurons (Parri and Crunelli, 2001; Parri et al., 2001). Projections from the thalamus to the cortex are complex and still not fully understood. However, a useful working model suggests that the higherfrequency oscillations are confined to a small neuronal space, 
A

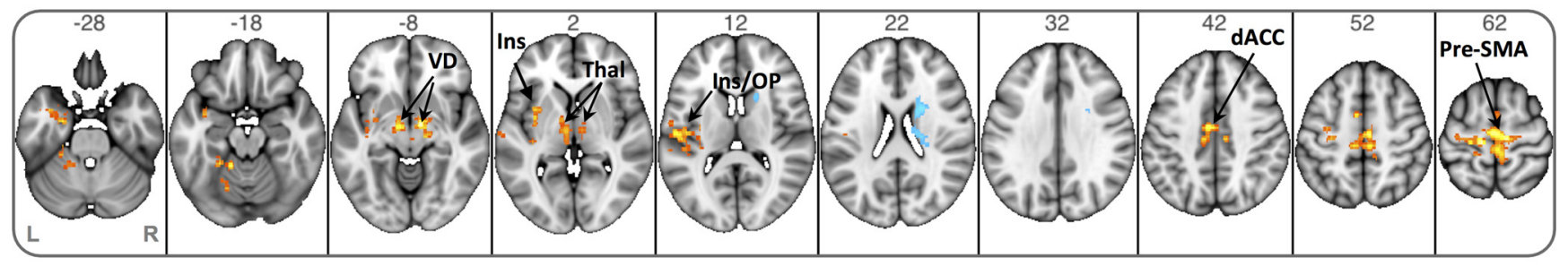

B
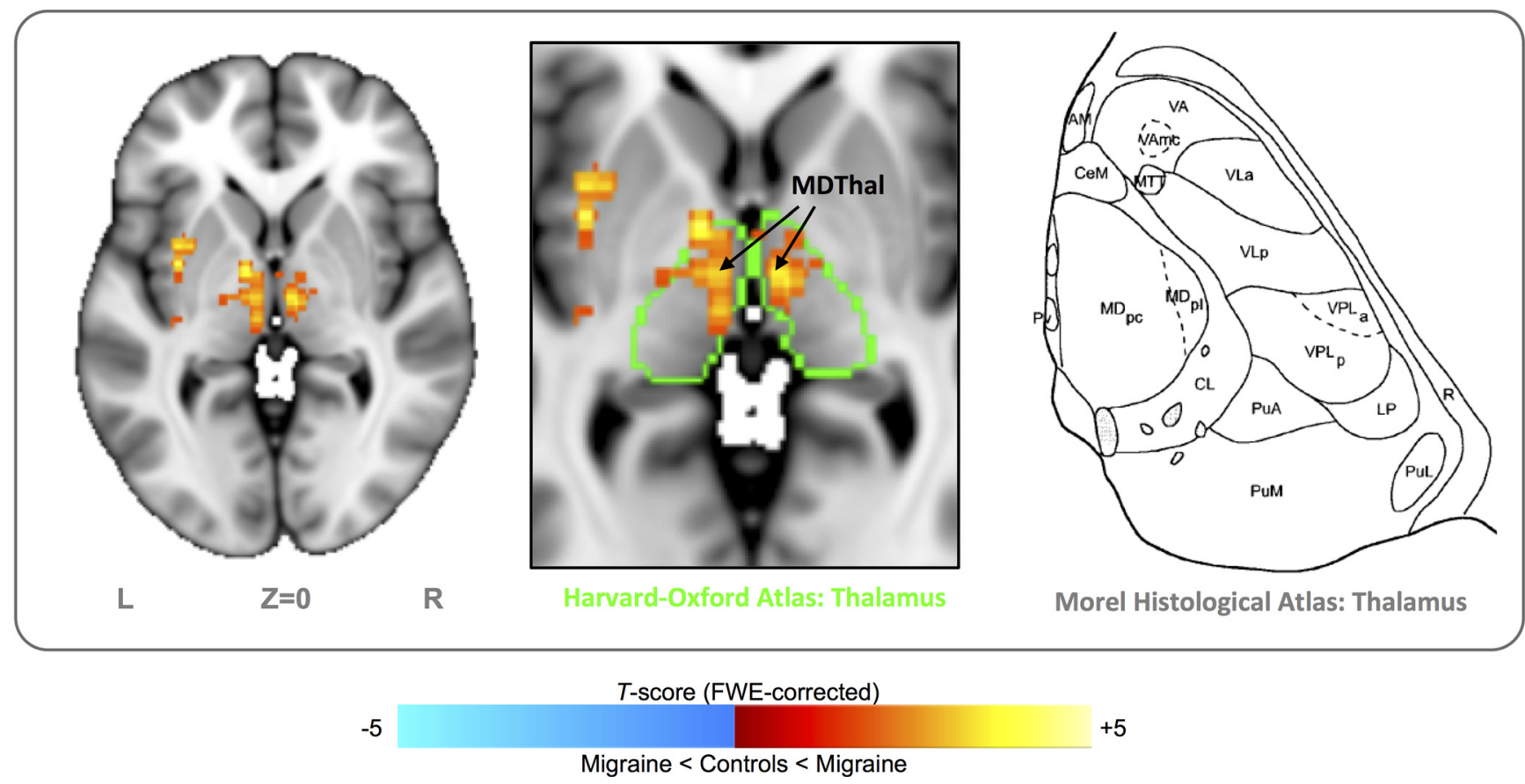

Figure 3. $A$, Increased amplitude of the LFOs in thalamocortical circuits. The statistical maps illustrate the differences in fALFF between migraine patients and healthy controls in the frequency band slow-4 (0.027-0.073 Hz). B, Increased amplitude of the LFOs in higher-order thalamic relays. Localization of the thalamus according to the Harvard-0xford subcortical atlas (green line). An axial section based on a histological atlas of the human thalamus is shown with nuclei outlined by black lines (Morel et al., 1997). All statistical images are displayed with a cluster probability threshold of $p<0.05$, corrected for multiple comparisons (familywise error, FWE). R (right) and L (left) indicate image orientations for slices in the Z plane. VD, Ventral diencephalon; Thal, thalamus; Ins/OP, insula/operculum; dACC, dorsal anterior cingulate cortex; MDThal, medial dorsal thalamus.

whereas very large networks are recruited during slow oscillations (Contreras and Llinas, 2001; Steriade, 2001; Csicsvari et al., 2003). Of the cortical areas exhibiting increased LFO amplitudes in migraine, we note that many of these brain areas and their experimentally observed frequency ranges show considerable overlap with abnormalities observed in patients suffering from chronic pain (Malinen et al., 2010; Baliki et al., 2011; Hong et al., 2013; Otti et al., 2013; Alshelh et al., 2016) (Fig. 3A). In addition, we observed dysrhythmia in several subcortical diencephalon structures (including hypothalamus and thalamus), which are known to play a key role in migraine and its associated symptoms (Akerman et al., 2011; Noseda et al., 2011; Kagan et al., 2013; Burstein et al., 2015). Considering the evidence, we suggest that the increased LFO activity likely underpins increased thalamocortical oscillations and the presence of interictal thalamocortical dysrhythmia in migraine (Coppola et al., 2007b).

\section{Increased LFOs in the medial thalamus}

Rhythmic cortical feedback to the thalamus is a major factor in the amplification of thalamocortical oscillations (Steriade, 2001; Destexhe and Sejnowski, 2003; Steriade and Timofeev, 2003).
Here, we took advantage of the relatively high spatial resolution of resting-state fMRI to examine the spatial and temporal characteristics of the oscillatory activity in the thalamus structure (Figs. 3, 4). Our results indicate that the main source of arrhythmic activity was localized to the higher-order relays of the medial dorsal nucleus. These nuclei have been shown to relay information from one cortical area to another cortical area via an extensive network of feedback projections (Guillery, 1995; Sherman and Guillery, 2002), which may serve a modulatory role in sensory processing. These driver versus modulator components of the thalamus (Sherman and Guillery, 1998) may be important in separating migraine (which is idiopathic in nature) from chronic neuropathic pain disorders. For example, recent work in patients with trigeminal neuropathy appears to show increased LFOs in the ascending (lateral) pain system, which is essential for mediating the sensory-discriminative features of neuropathic pain (Alshelh et al., 2016). A critical mechanism in migraine may therefore involve higher-order thalamic relays (including the medial dorsal nucleus) adjusting cortical synchrony and oscillatory patterns in the cortex (Sherman and Guillery, 1996; Li et al., 2003; Ramcharan et al., 2005; Van Horn and Sherman, 2007). Indeed, 
A

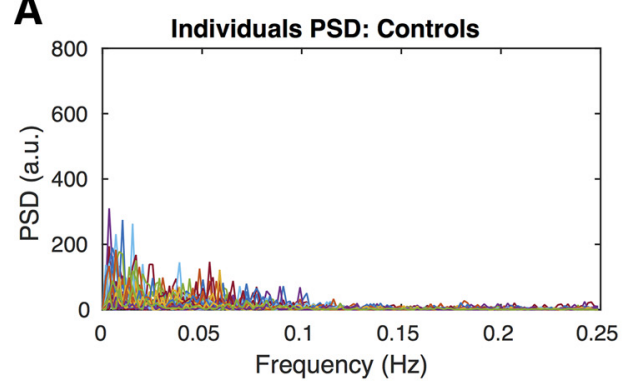

C

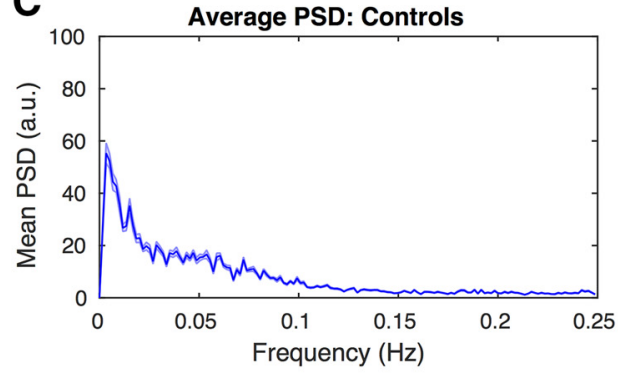

B
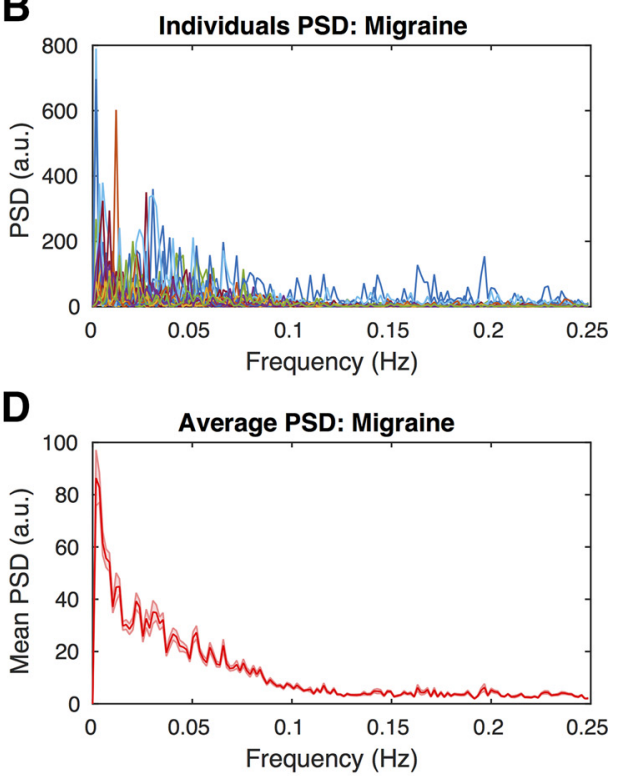

E

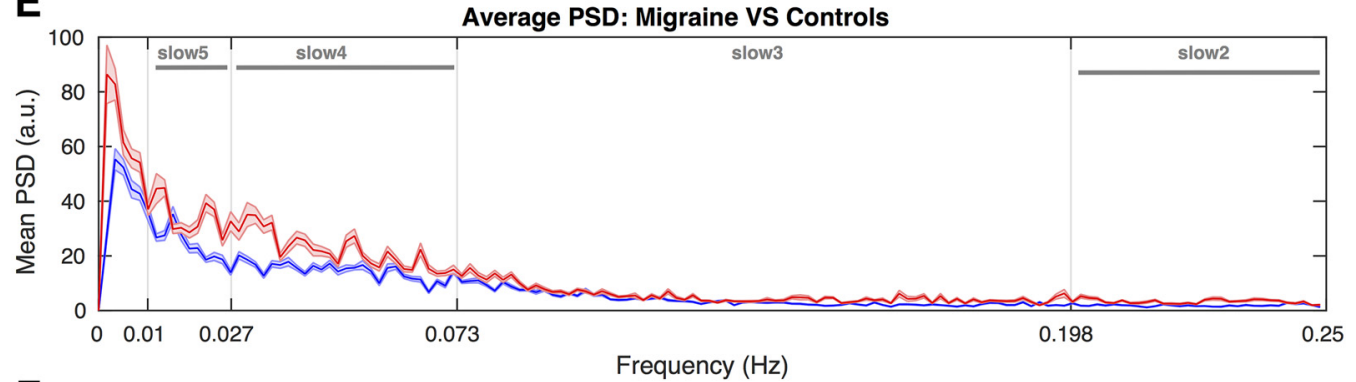

$\mathbf{F}$

Log average PSD: Migraine VS Controls

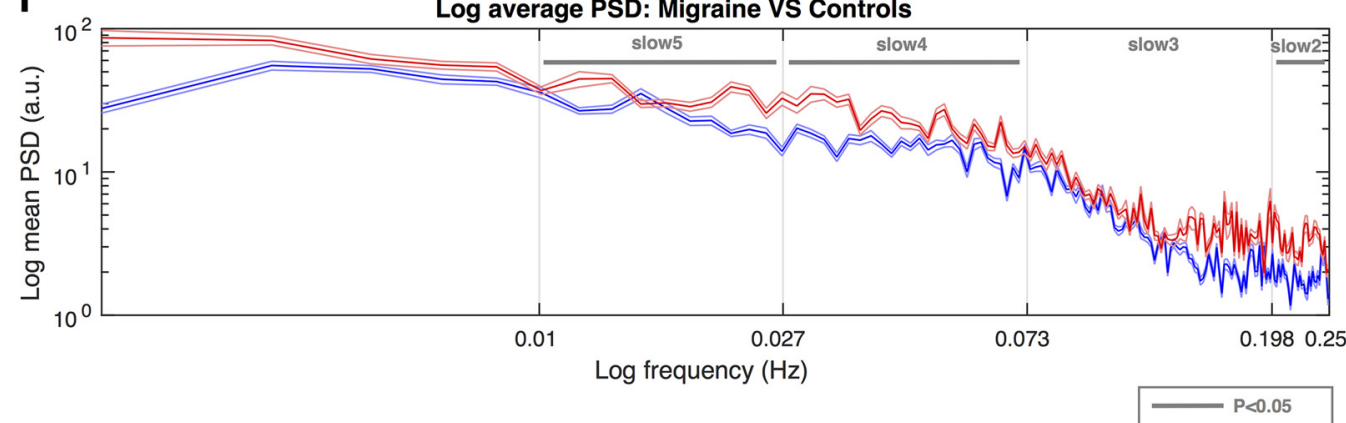

Figure 4. Power spectra analysis of LFOs in the thalamus. $A, B$, Individual PSD of LFOs in the thalamus of migraine patients $(n=40)$ and healthy controls $(n=40)$. C, $\boldsymbol{D}$, Group averages $( \pm$ SEM) of PSD in the thalamus. $E, F$, Expanded PSD covering the four frequency bands for linear and log scaled data. Red line indicates migraine; blue line, controls).

there appears to be a requirement for a particular architecture and connectivity of the thalamus in mediating ongoing cortical functions (Sherman, 2016), which may be altered in patients with migraine (Ellerbrock et al., 2013; Coppola et al., 2014; Chong and Schwedt, 2015; Magon et al., 2015). We favor the hypothesis that aberrant synchronization of oscillatory activity plays a role in disrupting higher-order multisensory processing in migraine, affecting the efficacy of information transmission across distributed brain networks (Singer, 1999; Engel et al., 2001). Further studies are needed to establish a causal role for the higher-order thalamus in regulating the synchrony between cortical neurons and cranial vascular nerves that are central to migraine pathophysiology (Edvinsson, 2011; Villanueva and Noseda, 2013).
Association between thalamic LFOs and headache frequency Neural correlates of the clinical symptoms and manifestations of migraine are potentially useful measures to aid stratification of patients. Here, we revealed that spontaneous LFOs in the thalamus are selectively associated with headache attack frequency, but not the duration of illness or age of the patients (Fig. 5). The varying amplitude of dysrhythmia could be an inherited genetic defect that alters LFO in the thalamus, thus predisposing patients to recurrent attacks. Alternatively, it might be the consequence of repeat attacks on the brain, thus making patients more vulnerable to progression from occasional to frequent migraines (Borsook et al., 2012). Related to the frequency of the attacks is the identification of trigger factors or premonitory features that reliably predict headache onset in migraine (Lipton et al., 2014; Pavlovic et 


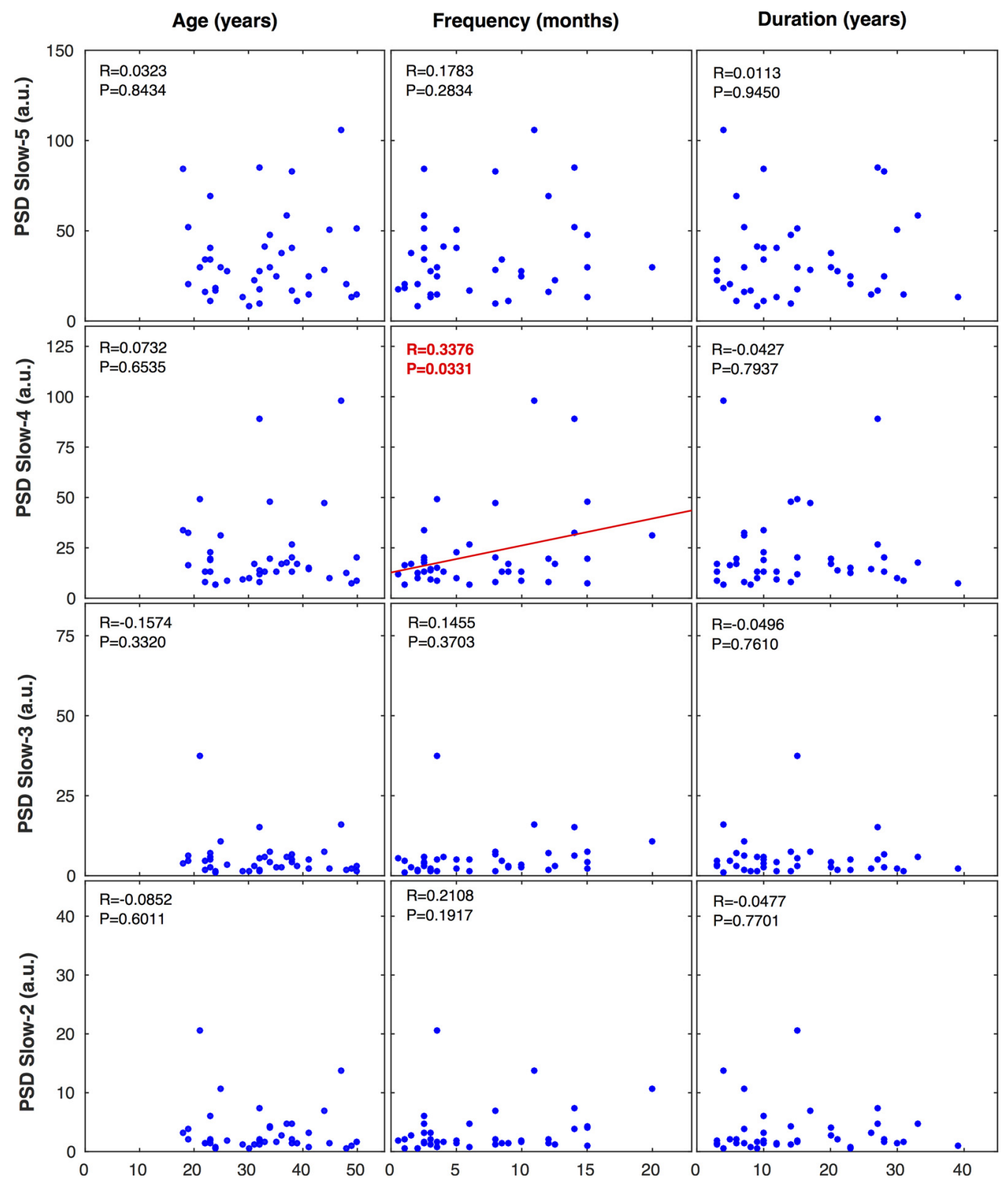

Figure 5. Correlations comparing clinical reported variables and PSD in the thalamus. Each patient's average PSD was calculated according to the four frequency bands and plotted against their age, current frequency of attacks, and disease duration. Pearson's correlation coefficient $(R)$ and associated $p$-values $(P)$ are reported for comparison.

al., 2014). We speculate that the neuronal oscillations are important in this process and could help to explain the sensitivity of the brain to such triggers at any given time. Moreover, it is still not clear how preventative therapies work, although from experimental models, evidence is accumulating that they may act centrally through a modulation of thalamic activity (Shields and Goadsby, 2005; Andreou et al., 2010; Andreou and Goadsby, 2011). The mechanisms underpinning these complex changes are far from being understood and we recognize that these intricate processes not only differ in the interictal phase of migraine, but also vary according to the phases of the migraine cycle in the same patient. Nevertheless, because the diagnosis of migraine is based on patient history (Headache Classification Subcommittee of the International Headache Society, 2004), these data establish an important link between interictal brain function and the clinical status of migraine patients at the time of their scans.

\section{Limitations and future perspectives}

There are several limitations of our study that should be noted. First, concerns have been raised surrounding the potential effects of physiological processes (i.e., cardio-respiratory events) that may introduce artifactual signals in the low-frequency range (Birn et al., 2006; Chang et al., 2009; Yan et al., 2009; van Buuren et al., 2009). We were unable to perform simultaneous measurements of cardiac and respiratory activity during the resting-state scan. However, recent work quantifying the test-retest reliability of f/ALFF measurements in response to breath holding - a process that strongly manipulates the hemodynamic contributions of the BOLD signal- has demonstrated good reproducibility (Zuo et al., 2010). Further mitigating this concern is the fact that we used f/ALFF instead of ALFF, which has been shown to be more effective at reducing signal artifacts in perivascular, periventricular, and periaqueductal bordering regions (Zuo et al., 2010). Second, migraine patients use a variety of analgesic 
drugs over many years, which might confound the observed functional brain changes. Having demonstrated that neither the patient's age nor disease duration is associated with the oscillatory activity, we suggest that certain comorbid factors such as the duration of treatment can be excluded. However, we do not control for the intake of different classes of medication. This remains an important issue for clinical pain and headache research.

\section{Conclusion}

Converging lines of evidence suggest that the CNS plays a crucial role in the predisposition to develop different forms of migraine (Goadsby et al., 2009; Pietrobon and Moskowitz, 2013; Burstein et al., 2015; Ferrari et al., 2015). Here, we present the first imaging data that demonstrate the presence of abnormal LFOs in thalamocortical networks of patients with migraine, confirming an abnormal interictal state of thalamocortical dysrhythmia. Given that spontaneous LFOs in the thalamus are selectively associated with headache attack frequency, this suggests that the varying amplitude of dysrhythmia could be an innate genetic defect that predisposes patients to recurrent attacks. Alternatively, it might be the consequence of repeated attacks on the brain, thus making patients more vulnerable to progression from occasional to frequent migraines. Rhythmic cortical feedback to the thalamus is a major factor in the amplification of thalamocortical oscillations, making it a strong candidate for influencing neuronal excitability. We further speculate that the intrinsic dynamics of thalamocortical network oscillations are crucial for early sensory processing and thus could underlie important pathophysiological processes involved in multisensory integration.

\section{References}

Akerman S, Holland PR, Goadsby PJ (2011) Diencephalic and brainstem mechanisms in migraine. Nat Rev Neurosci 12:570-584. CrossRef Medline

Alshelh Z, Di Pietro F, Youssef AM, Reeves JM, Macey PM, Vickers ER, Peck CC, Murray GM, Henderson LA (2016) Chronic neuropathic pain: it's about the rhythm. J Neurosci 36:1008-1018. CrossRef Medline

Andreou AP, Goadsby PJ (2011) Topiramate in the treatment of migraine: a kainate (glutamate) receptor antagonist within the trigeminothalamic pathway. Cephalalgia 31:1343-1358. CrossRef Medline

Andreou AP, Shields KG, Goadsby PJ (2010) GABA and valproate modulate trigeminovascular nociceptive transmission in the thalamus. Neurobiol Dis 37:314-323. CrossRef Medline

Antal A, Kriener N, Lang N, Boros K, Paulus W (2011) Cathodal transcranial direct current stimulation of the visual cortex in the prophylactic treatment of migraine. Cephalalgia 31:820-828. CrossRef Medline

Azevedo FA, Carvalho LR, Grinberg LT, Farfel JM, Ferretti RE, Leite RE, Jacob Filho W, Lent R, Herculano-Houzel S (2009) Equal numbers of neuronal and nonneuronal cells make the human brain an isometrically scaled-up primate brain. J Comp Neurol 513:532-541. CrossRef Medline

Bahra A, Matharu MS, Buchel C, Frackowiak RS, Goadsby PJ (2001) Brainstem activation specific to migraine headache. Lancet 357:1016-1017. CrossRef Medline

Baliki MN, Baria AT, Apkarian AV (2011) The cortical rhythms of chronic back pain. J Neurosci 31:13981-13990. CrossRef Medline

Birn RM, Diamond JB, Smith MA, Bandettini PA (2006) Separating respiratory-variation-related fluctuations from neuronal-activity-related fluctuations in fMRI. Neuroimage 31:1536-1548. CrossRef Medline

Biswal B, Yetkin FZ, Haughton VM, Hyde JS (1995) Functional connectivity in the motor cortex of resting human brain using echo-planar MRI. Magn Reson Med 34:537-541. CrossRef Medline

Borsook D, Maleki N, Becerra L, McEwen B (2012) Understanding migraine through the lens of maladaptive stress responses: a model disease of allostatic load. Neuron 73:219-234. CrossRef Medline

Boyer N, Dallel R, Artola A, Monconduit L (2014) General trigeminospinal central sensitization and impaired descending pain inhibitory controls contribute to migraine progression. Pain 155:1196-1205. CrossRef Medline

Buckner RL, Andrews-Hanna JR, Schacter DL (2008) The brain's default network: anatomy, function, and relevance to disease. Ann N Y Acad Sci 1124:1-38. CrossRef Medline

Burstein R, Noseda R, Borsook D (2015) Migraine: multiple processes, complex pathophysiology. J Neurosci 35:6619-6629. CrossRef Medline

Buzsáki G, Draguhn A (2004) Neuronal oscillations in cortical networks. Science 304:1926-1929. CrossRef Medline

Buzsáki G, Bickford RG, Ponomareff G, Thal LJ, Mandel R, Gage FH (1988) Nucleus basalis and thalamic control of neocortical activity in the freely moving rat. J Neurosci 8:4007-4026. Medline

Chang C, Cunningham JP, Glover GH (2009) Influence of heart rate on the BOLD signal: the cardiac response function. Neuroimage 44:857-869. CrossRef Medline

Chong CD, Schwedt TJ (2015) Migraine affects white-matter tract integrity: a diffusion-tensor imaging study. Cephalalgia 35:1162-1171. CrossRef Medline

Contreras D, Llinas R (2001) Voltage-sensitive dye imaging of neocortical spatiotemporal dynamics to afferent activation frequency. J Neurosci 21: 9403-9413. Medline

Coppola G, Pierelli F, Schoenen J (2007a) Is the cerebral cortex hyperexcitable or hyperresponsive in migraine? Cephalalgia 27:1427-1439. CrossRef Medline

Coppola G, Ambrosini A, Di Clemente L, Magis D, Fumal A, Gérard P, Pierelli F, Schoenen J (2007b) Interictal abnormalities of gamma band activity in visual evoked responses in migraine: an indication of thalamocortical dysrhythmia? Cephalalgia 27:1360-1367. CrossRef Medline

Coppola G, Di Lorenzo C, Schoenen J, Pierelli F (2013) Habituation and sensitization in primary headaches. J Headache Pain 14:65. CrossRef Medline

Coppola G, Tinelli E, Lepre C, Iacovelli E, Di Lorenzo C, Di Lorenzo G, Serrao M, Pauri F, Fiermonte G, Bianco F, Pierelli F (2014) Dynamic changes in thalamic microstructure of migraine without aura patients: a diffusion tensor magnetic resonance imaging study. Eur J Neurol 21:287-e13. CrossRef Medline

Cordes D, Haughton VM, Arfanakis K, Carew JD, Turski PA, Moritz CH, Quigley MA, Meyerand ME (2001) Frequencies contributing to functional connectivity in the cerebral cortex in "resting-state" data. AJNR Am J Neuroradiol 22:1326-1333. Medline

Csicsvari J, Jamieson B, Wise KD, Buzsáki G (2003) Mechanisms of gamma oscillations in the hippocampus of the behaving rat. Neuron 37:311-322. CrossRef Medline

Deco G, Jirsa VK, McIntosh AR (2011) Emerging concepts for the dynamical organization of resting-state activity in the brain. Nat Rev Neurosci 12:43-56. CrossRef Medline

De Luca M, Beckmann CF, De Stefano N, Matthews PM, Smith SM (2006) fMRI resting state networks define distinct modes of long-distance interactions in the human brain. Neuroimage 29:1359-1367. CrossRef Medline

Destexhe A, Sejnowski TJ (2003) Interactions between membrane conductances underlying thalamocortical slow-wave oscillations. Physiol Rev 83: 1401-1453. CrossRef Medline

de Tommaso M, Ambrosini A, Brighina F, Coppola G, Perrotta A, Pierelli F, Sandrini G, Valeriani M, Marinazzo D, Stramaglia S, Schoenen J (2014) Altered processing of sensory stimuli in patients with migraine. Nat Rev Neurol 10:144-155. CrossRef Medline

Di Clemente L, Coppola G, Magis D, Fumal A, De Pasqua V, Di Piero V, Schoenen J (2007) Interictal habituation deficit of the nociceptive blink reflex: an endophenotypic marker for presymptomatic migraine? Brain 130:765-770. CrossRef Medline

Diener HC, Charles A, Goadsby PJ, Holle D (2015) New therapeutic approaches for the prevention and treatment of migraine. Lancet Neurol 14:1010-1022. CrossRef Medline

Edvinsson L (2011) Tracing neural connections to pain pathways with relevance to primary headaches. Cephalalgia 31:737-747. CrossRef Medline

Ellerbrock I, Engel AK, May A (2013) Microstructural and network abnormalities in headache. Curr Opin Neurol 26:353-359. CrossRef Medline

Engel AK, Fries P, Singer W (2001) Dynamic predictions: oscillations and synchrony in top-down processing. Nat Rev Neurosci 2:704-716. CrossRef Medline

Ferrari MD, Klever RR, Terwindt GM, Ayata C, van den Maagdenberg AM (2015) Migraine pathophysiology: lessons from mouse models and human genetics. Lancet Neurol 14:65-80. CrossRef Medline

Fox MD, Raichle ME (2007) Spontaneous fluctuations in brain activity ob- 
served with functional magnetic resonance imaging. Nat Rev Neurosci 8:700-711. CrossRef Medline

Fox MD, Snyder AZ, Vincent JL, Corbetta M, Van Essen DC, Raichle ME (2005) The human brain is intrinsically organized into dynamic, anticorrelated functional networks. Proc Natl Acad Sci U S A 102:9673-9678. CrossRef Medline

Goadsby PJ, Charbit AR, Andreou AP, Akerman S, Holland PR (2009) Neurobiology of migraine. Neuroscience 161:327-341. CrossRef Medline

Guillery RW (1995) Anatomical evidence concerning the role of the thalamus in corticocortical communication: a brief review. J Anat 187:583-592. Medline

Hansen JM, Goadsby PJ, Charles AC (2016) Variability of clinical features in attacks of migraine with aura. Cephalalgia 36:216-224. CrossRef Medline

Headache Classification Subcommittee of the International Headache Society (2004) The International Classification of Headache Disorders: 2nd edition. Cephalalgia 24:9-160. CrossRef Medline

Hong JY, Kilpatrick LA, Labus J, Gupta A, Jiang Z, Ashe-McNalley C, Stains J, Heendeniya N, Ebrat B, Smith S, Tillisch K, Naliboff B, Mayer EA (2013) Patients with chronic visceral pain show sex-related alterations in intrinsic oscillations of the resting brain. J Neurosci 33:11994-12002. CrossRef Medline

Hughes SW, Lorincz ML, Parri HR, Crunelli V (2011) Infraslow $(<0.1 \mathrm{~Hz})$ oscillations in thalamic relay nuclei basic mechanisms and significance to health and disease states. Prog Brain Res 193:145-162. CrossRef Medline

Kagan R, Kainz V, Burstein R, Noseda R (2013) Hypothalamic and basal ganglia projections to the posterior thalamus: possible role in modulation of migraine headache and photophobia. Neuroscience 248:359-368. CrossRef Medline

Küblböck M, Woletz M, Höflich A, Sladky R, Kranz GS, Hoffmann A, Lanzenberger R, Windischberger C (2014) Stability of low-frequency fluctuation amplitudes in prolonged resting-state fMRI. Neuroimage 103: 249-257. CrossRef Medline

Li J, Bickford ME, Guido W (2003) Distinct firing properties of higher order thalamic relay neurons. J Neurophysiol 90:291-299. CrossRef Medline

Lipton RB, Pavlovic JM, Haut SR, Grosberg BM, Buse DC (2014) Methodological issues in studying trigger factors and premonitory features of migraine. Headache 54:1661-1669. CrossRef Medline

Logothetis NK (2008) What we can do and what we cannot do with fMRI. Nature 453:869-878. CrossRef Medline

Lüthi A, McCormick DA (1998) Periodicity of thalamic synchronized oscillations: the role of $\mathrm{Ca} 2+$-mediated upregulation of Ih. Neuron 20: 553-563. CrossRef Medline

Magon S, May A, Stankewitz A, Goadsby PJ, Tso AR, Ashina M, Amin FM, Seifert CL, Chakravarty MM, Müller J, Sprenger T (2015) Morphological abnormalities of thalamic subnuclei in migraine: a multicenter MRI study at 3 tesla. J Neurosci 35:13800-13806. CrossRef Medline

Malinen S, Vartiainen N, Hlushchuk Y, Koskinen M, Ramkumar P, Forss N, Kalso E, Hari R (2010) Aberrant temporal and spatial brain activity during rest in patients with chronic pain. Proc Natl Acad Sci U S A 107: 6493-6497. CrossRef Medline

McCormick DA (2002) Cortical and subcortical generators of normal and abnormal rhythmicity. Int Rev Neurobiol 49:99-114. CrossRef Medline

Morel A, Magnin M, Jeanmonod D (1997) Multiarchitectonic and stereotactic atlas of the human thalamus. J Comp Neurol 387:588-630. CrossRef Medline

Noseda R, Jakubowski M, Kainz V, Borsook D, Burstein R (2011) Cortical projections of functionally identified thalamic trigeminovascular neurons: implications for migraine headache and its associated symptoms. J Neurosci 31:14204-14217. CrossRef Medline

Otti A, Guendel H, Wohlschläger A, Zimmer C, Noll-Hussong M (2013) Frequency shifts in the anterior default mode network and the salience network in chronic pain disorder. BMC Psychiatry 13:84. CrossRef Medline

Parri HR, Crunelli V (2001) Pacemaker calcium oscillations in thalamic astrocytes in situ. Neuroreport 12:3897-3900. CrossRef Medline

Parri HR, Gould TM, Crunelli V (2001) Spontaneous astrocytic Ca2+ oscillations in situ drive NMDAR-mediated neuronal excitation. Nat Neurosci 4:803-812. CrossRef Medline

Pavlovic JM, Buse DC, Sollars CM, Haut S, Lipton RB (2014) Trigger factors and premonitory features of migraine attacks: summary of studies. Headache 54:1670-1679. CrossRef Medline

Penttonen M, Buzsáki G (2003) Natural logarithmic relationship between brain oscillators. Thalamus and Related Systems 2:145-152.
Pietrobon D, Moskowitz MA (2013) Pathophysiology of migraine. Annu Rev Physiol 75:365-391. CrossRef Medline

Power JD, Schlaggar BL, Petersen SE (2014) Studying brain organization via spontaneous fMRI signal. Neuron 84:681-696. CrossRef Medline

Raichle ME, Mintun MA (2006) Brain work and brain imaging. Annu Rev Neurosci 29:449-476. CrossRef Medline

Raichle ME, MacLeod AM, Snyder AZ, Powers WJ, Gusnard DA, Shulman GL (2001) A default mode of brain function. Proc Natl Acad Sci U S A 98:676-682. CrossRef Medline

Ramcharan EJ, Gnadt JW, Sherman SM (2005) Higher-order thalamic relays burst more than first-order relays. Proc Natl Acad Sci U S A 102: 12236-12241. CrossRef Medline

Salvador R, Martínez A, Pomarol-Clotet E, Gomar J, Vila F, Sarró S, Capdevila A, Bullmore E (2008) A simple view of the brain through a frequencyspecific functional connectivity measure. Neuroimage 39:279-289. CrossRef Medline

Sándor PS, Afra J, Proietti-Cecchini A, Albert A, Schoenen J (1999) Familial influences on cortical evoked potentials in migraine. Neuroreport 10: 1235-1238. CrossRef Medline

Schoenen J (1996) Deficient habituation of evoked cortical potentials in migraine: a link between brain biology, behavior and trigeminovascular activation? Biomed Pharmacother 50:71-78. CrossRef Medline

Sherman SM (2016) Thalamus plays a central role in ongoing cortical functioning. Nat Neurosci 16:533-541. CrossRef Medline

Sherman SM, Guillery RW (1996) Functional organization of thalamocortical relays. J Neurophysiol 76:1367-1395. Medline

Sherman SM, Guillery RW (1998) On the actions that one nerve cell can have on another: distinguishing "drivers" from "modulators." Proc Natl Acad Sci U S A 95:7121-7126. CrossRef Medline

Sherman SM, Guillery RW (2002) The role of the thalamus in the flow of information to the cortex. Philos Trans R Soc Lond B Biol Sci 357: 1695-1708. CrossRef Medline

Shields KG, Goadsby PJ (2005) Propranolol modulates trigeminovascular responses in thalamic ventroposteromedial nucleus: a role in migraine? Brain 128:86-97. Medline

Singer W (1999) Neuronal synchrony: a versatile code for the definition of relations? Neuron 24:49-65,111-125. Medline

Siniatchkin M, Kropp P, Gerber WD, Stephani U (2000) Migraine in childhood-are periodically occurring migraine attacks related to dynamic changes of cortical information processing? Neurosci Lett 279: 1-4. CrossRef Medline

Siniatchkin M, Kropp P, Gerber WD (2001) Contingent negative variation in subjects at risk for migraine without aura. Pain 94:159-167. CrossRef Medline

Steriade M (2001) Impact of network activities on neuronal properties in corticothalamic systems. J Neurophysiol 86:1-39. Medline

Steriade M, Timofeev I (2003) Neuronal plasticity in thalamocortical networks during sleep and waking oscillations. Neuron 37:563-576. CrossRef Medline

Teepker M, Hötzel J, Timmesfeld N, Reis J, Mylius V, Haag A, Oertel WH, Rosenow F, Schepelmann K (2010) Low-frequency rTMS of the vertex in the prophylactic treatment of migraine. Cephalalgia 30:137-144. CrossRef Medline

Vaishnavi SN, Vlassenko AG, Rundle MM, Snyder AZ, Mintun MA, Raichle ME (2010) Regional aerobic glycolysis in the human brain. Proc Natl Acad Sci U S A 107:17757-17762. CrossRef Medline

van Buuren M, Gladwin TE, Zandbelt BB, van den Heuvel M, Ramsey NF, Kahn RS, Vink M (2009) Cardiorespiratory effects on default-mode network activity as measured with fMRI. Hum Brain Mapp 30:3031-3042. CrossRef Medline

Van Horn SC, Sherman SM (2007) Fewer driver synapses in higher order than in first order thalamic relays. Neuroscience 146:463-470. CrossRef Medline

Viana M, Sances G, Ghiotto N, Guaschino E, Allena M, Nappi G, Goadsby PJ, Tassorelli C (2015) Variability of the characteristics of a migraine attack within patients. Cephalalgia. In press.

Viganò A, D’Elia TS, Sava SL, Auvé M, De Pasqua V, Colosimo A, Di Piero V, Schoenen J, Magis D (2013) Transcranial Direct Current Stimulation (tDCS) of the visual cortex: a proof-of-concept study based on interictal electrophysiological abnormalities in migraine. J Headache Pain 14:23. CrossRef Medline 
Villanueva L, Noseda R (2013) Trigeminal mechanisms of nociception. In: Wall and Melzack's textbook of pain, pp 793-802. New York: Elsevier.

Vos T, Flaxman AD, Naghavi M, Lozano R, Michaud C, Ezzati M, Shibuya K, Salomon JA, Abdalla S, Aboyans V, Abraham J, Ackerman I, Aggarwal R, Ahn SY, Ali MK, Alvarado M, Anderson HR, Anderson LM, Andrews KG, Atkinson C, et al. (2012) Years lived with disability (YLDs) for 1160 sequelae of 289 diseases and injuries 1990-2010: a systematic analysis for the Global Burden of Disease Study 2010. Lancet 380:2163-2196. CrossRef Medline

Yan L, Zhuo Y, Ye Y, Xie SX, An J, Aguirre GK, Wang J (2009) Physiological origin of low-frequency drift in blood oxygen level dependent (BOLD) functional magnetic resonance imaging (fMRI). Magn Reson Med 61: 819-827. CrossRef Medline
Zang YF, He Y, Zhu CZ, Cao QJ, Sui MQ, Liang M, Tian LX, Jiang TZ, Wang YF (2007) Altered baseline brain activity in children with ADHD revealed by resting-state functional MRI. Brain Dev 29:83-91. CrossRef Medline

Zou QH, Zhu CZ, Yang Y, Zuo XN, Long XY, Cao QJ, Wang YF, Zang YF (2008) An improved approach to detection of amplitude of lowfrequency fluctuation (ALFF) for resting-state fMRI: fractional ALFF. J Neurosci Methods 172:137-141. CrossRef Medline

Zuo XN, Di Martino A, Kelly C, Shehzad ZE, Gee DG, Klein DF, Castellanos FX, Biswal BB, Milham MP (2010) The oscillating brain: complex and reliable. Neuroimage 49:1432-1445. CrossRef Medline 